* Especialista em Filosofia Política e Jurídica pela pela Universidade Estadual de Londrina (UEL) e em Direito do Trabalho e Direito Processual do Trabalho pela Pontifícia Universidade Católica do Paraná (PUC-PR). Graduada em Direito pela UEL. Graduanda em Letras-Francês pela UEL. E-mail: brunabpaula@gmail.com

\footnotetext{
**Doutor em Direito Econômico e Socioambiental pela Pontifícia Universidade Católica do Paraná (PUC-PR). Mestre em Direito Negocial pela Universidade Estadual de Londrina (UEL). Especialista em Direito Civil e Processo Civil pela Universidade do Norte do Paraná (UENP). Graduado em Direito pela UEL. Professor da Especialização em Direito do Trabalho e Direito Processual do Trabalho na PUCPR. Professor Adjunto do Curso de Direito PUC-PR - Campus Londrina e Professor Assistente da UEL. E-mail: alberto.ribeiro@ pucpr.br
}

\section{Discriminação no Trabalho e Antecedentes Criminais: AÇões Afirmativas e Estudo de Caso no Patronato Municipal de Apucarana - Paraná}

\author{
Discrimination at Work AND CRIMINAL RECORdS: \\ Affirmative Actions AND a Case-Study of The County \\ of APUCARANA - PARANÁ (BRAZIL)
}

\section{Bruna Balthazar de Paula* Luiz Alberto Pereira Ribeiro**}

Como citar: PAULA, Bruna Balthazar de; RIBEIRO, LuizAlberto Pereira. Discriminação no trabalho e antecedentes criminais: ações afirmativas e estudo de caso no patronato municipal de Apucarana - Paraná. Revista do Direito Público, Londrina, v. 15, n. 1, p. 10-25, abr. 2020. DOI: 10.5433/24157-108104-1.2020v15 n1p. 10. ISSN: 1980-511X

Resumo: O Direito ao Trabalho está previsto no rol de direitos sociais na Constituição Federal de 1988 e, assim, constitui direito fundamental social, que deve ser garantido a todos, sem qualquer distinção. A discriminação no trabalho é vedada no plano nacional pela Constituição e normas infraconstitucionais, bem como no plano internacional, especificamente, pela Convenção n. 111 da OIT, seja no período pré-contratual, contratual ou pós-contratual. A não contratação pelo empregador de indivíduos que possuam antecedentes criminais ofende o princípio da igualdade, inibindo a efetivação do direito fundamental ao trabalho, e constitui abuso de poder do empregador, pois caminha em sentido contrário ao ordenamento jurídico internacional e brasileiro. Por constituir prática discriminatória, há no Brasil a adoção de ações afirmativas que buscam reduzir esta desigualdade, sendo o principal o Projeto Começar de Novo do Conselho Nacional de Justiça. A política criminal brasileira tem como uma de suas bases a ressocialização dos egressos por meio da inserção no mercado de trabalho pela criação de políticas públicas específicas para este fim. Buscouse verificar se a prática da exigência de apresentação de certidão de Antecedentes Criminais, de fato, ocorre, mediante a aplicação de questionário aos apenados em regime aberto no Patronato Municipal de Apucarana.

Palavras-chave: Discriminação no trabalho. Antecedentes criminais. Ação afirmativa. Ressocialização. 
Abstract: The Right to Work is listed as one of the many social rights of the Brazilian Federal Constitution of 1988. In other words, it is a fundamental social right that must be upheld by the State and all its citizens. Therefore, any form of workplace discrimination is prohibited by the Brazilian Constitution and infra-constitutional norms, as well as at the international level, specifically by the ILO Convention no. 111, in its pre-contractual, contractual or post-contractual form. The failure of the employer to hire individuals with criminal records offends the principle of equality, inhibiting the realization of their fundamental right to work, and constitutes an abuse of the employer's power, since it goes against the international and Brazilian legal system. Because it is a discriminatory practice, Brazil adopts affirmative actions in order to reduce this inequality, the main one being the "Projeto Começar de Novo" (Starting Again Project) of the National Council of Justice. One of the most fundamental pillars of Brazilian criminal system is the re-socialization of prison inmates with the use of specific public policies in order for them to enter the workforce. This paper sought to verify whether the practice of requiring the presentation of a Criminal Background Certificate, in fact, occurs, through the application of a questionnaire to those convicted in an open regime at the Municipal Patronage of Apucarana.

Keywords: Discrimination at work. Criminal Background. Affirmative Actions. Re-socialization. 


\section{INTRODUÇÃO}

O Direito ao Trabalho está previsto no rol de direitos sociais, econômicos e culturais, na Constituição Federal, no plano nacional, e no plano internacional nos tratados de Direitos Humanos. Sendo assim, por tratar-se de direito fundamental social, privilegiado no ordenamento jurídico, possui eficácia e vincula os particulares.

É neste âmbito que ganha destaque o princípio da igualdade, o qual, em seu sentido material, determina que a todos deve ser garantida a igualdade de oportunidades. A Constituição de 1988 privilegia o referido princípio ao prever a igualdade de todos perante a lei, mas também ao elencar como objetivos da República a erradicação da marginalização, a redução de desigualdades sociais e a promoção do bem de todos, sem preconceitos e quaisquer formas de discriminação.

Seguindo os princípios constitucionais, a legislação infraconstitucional vedou, expressamente, condutas discriminatórias e inibitórias do direito ao trabalho, sendo que as condutas que se pautem em critério de discriminação e constituam obstáculo ao atingimento deste direito são passíveis de serem consideradas ilícitas.

Desta feita, o objeto do presente artigo pretende analisar se a existência da prática de exigência de certidão de Antecedentes Criminais pelo empregador em processo de admissão do empregado constitui-se conduta discriminatória e antijurídica.

Ainda, tratou o presente artigo de um estudo de caso com uma amostra de 20 (vinte) assistidos do Patronato Municipal de Apucarana, a fim de verificar a existência da referida prática no cotidiano dos processos seletivos de contratação de trabalhadores, por meio de um questionário com análise quantitativa. Ressalta-se que a intenção do trabalho é verificar se, de fato, a prática de não contratação de candidato com antecedentes criminais ocorre, utilizando como público-alvo, conforme já exposto, uma seleção de assistidos do Patronato Municipal de Apucarana.

\section{A DISCRIMINAÇÃO NO TRABALHO}

A igualdade, considerada um dos fundamentos básicos de um Estado Democrático de Direito, foi consagrada na Constituição de 1988 (BRASIL, 1988) que prevê "todos são iguais perante a lei" (artigo $5^{\circ}$ ) a fim de construir uma sociedade livre, justa e solidária, erradicando a pobreza e a redução das desigualdades sociais e regionais, promovendo o bem de todos, sem preconceitos de origem, raça, sexo, cor, idade e quaisquer outras formas de discriminação.

Dentro desse contexto ocupa destaque importante a questão o princípio da igualdade e da não discriminação no âmbito trabalhista, principalmente se a possibilidade de exigir antecedentes criminais no processo de pré-contratação do trabalhador não pode ser considerado um ato de discriminação.

Para tanto, se faz necessário discorrer sobre o que é discriminação, bem como o que se entende por ação afirmativa, relacionando com o direito do trabalho e com princípio da igualdade, particularmente por se tratar de direito fundamental.

\subsection{Igualdade e Ação Afirmativa}

A constitucionalização do princípio da igualdade ocorreu após o surgimento do Estado Moderno, em decorrência das Revoluções do final do século XVIII, surgindo de maneira formal, pois correspondia à máxima "todos são iguais perante a lei". Constituiu, assim, um fundamento do Estado Liberal burguês, visando acabar com privilégios de determinadas classes da sociedade (MENEZES et al., 2009, p. 76).

Essa concepção formal passou a ser questionada após a Revolução Industrial, quando começou a ser constatado que, na busca pela igualdade, apenas a simples declaração geral não seria 
suficiente para assegurá-la de fato, surgindo a necessidade da efetivação do respectivo princípio, principalmente para tornar acessíveis as oportunidades para quem era socialmente desfavorecido. Portanto, se um primeiro momento é marcado pela proteção geral com o temor da diferença, tratando o indivíduo de forma generalizada, passa-se a perceber a necessidade de individualização e diferenciação (PIOVESAN, 2005, p. 46).

A igualdade possui três vertentes, quais sejam: igualdade formal, que consiste no preceito "todos são iguais perante a lei"; igualdade material que corresponde à justiça social e distributiva; e a igualdade material que diz respeito à justiça como reconhecimento de identidades (PIOVESAN, 2005, p. 47).

Rothenburg (2008, p. 79) afirma que "repete-se à exaustão que se devem tratar igualmente os iguais e desigualmente os desiguais, na medida de sua desigualdade" e, não obstante sua generalidade, esclarece que essa máxima expressa o aspecto jurídico da igualdade, pois alude ao tratamento, quando afirma que as pessoas devem ser tratadas como iguais ou desiguais pelo Direito.

A Constituição de 1988 (BRASIL, 1988) prevê a igualdade formal como declaração geral no caput do artigo $5^{\circ}$, porém, resta claro que a igualdade que importa é a material, característica dos direitos sociais, ao estabelecer no artigo $3^{\circ}$, dentre os objetivos fundamentais da República, a erradicação da pobreza e da marginalização, bem como a redução das desigualdades e vedação de quaisquer formas de discriminação.

Assim, é possível afirmar que a não discriminação é decorrente do princípio da igualdade material, visto que é impossível compreender o que seja discriminação sem atrelá-la à igualdade. Nesse sentido, Mallet (2010, p. 17) esclarece a partir da definição de discriminação

Discriminação supõe desigualdade. Não qualquer desigualdade, [...] mas a desigualdade ilegítima, intolerável diante das circunstâncias e dos padrões então vigentes. Por isso que, se a justiça se relaciona com a igualdade e a igualdade repele a discriminação, a discriminação é também a negação da justiça.

Para Piovesan (2005, p. 48) a "discriminação ocorre quando somos tratados como iguais em situações diferentes e como diferentes em situações iguais". Assim, discriminar pode, portanto, ter dois sentidos: um pejorativo e outro que tem como significado apenas uma distinção.

No primeiro caso, também chamada de discriminação ilícita ou negativa, resulta do preconceito e constitui um fenômeno intergrupal voltado a determinado grupo de pessoas ou a uma pessoa específica, implicando em uma predisposição negativa (GUGEL, 2000, p. 18).

Assim, a discriminação ilícita consiste em toda exclusão, restrição, distinção ou preferência que tenha como objetivo ou resultado prejudicar ou anular o exercício dos direitos humanos e liberdades fundamentais, seja no campo político, econômico, social (incluindo no âmbito trabalhista), cultural, significando sempre uma desigualdade (PIOVESAN, 2005, p. 48).

No segundo caso, chamada de discriminação lícita ou positiva, esta consiste na distinção realizada para preservar o princípio da igualdade, ou seja, diferenciação legítima de indivíduos que se encontram em situações diferentes (SOUTO MAIOR, 2002,p. 97). Desta forma, a discriminação lícita ou positiva seria o dever de diferenciação sempre que este seja necessário para o alcance da igualdade efetiva (ROTHENBURG, 2008, p. 79, 82).

Bandeira de Mello (2004, p. 11) afirma que a discriminação é recebida como compatível com o princípio da igualdade apenas quando existe "um vínculo de correlação lógica entre a peculiaridade diferencial acolhida por residente no objeto e a desigualdade de tratamento em função dela conferida", ressaltando ao final que tal correlação deve ser compatível com os interesses prestigiados pela Constituição (MELLO, 2004, p. 17).

Conclui-se que a igualdade formal está relacionada à vedação de discriminações 
injustificadas (discriminação ilícita ou negativa) e a igualdade material está relacionada à exigência de tratamento distinto (discriminação lícita ou positiva), em sentido social de interferência do Estado.

No presente trabalho a discriminação ilícita será chamada apenas de discriminação e a discriminação lícita de ação afirmativa.

Em relação a ação afirmativa (“discriminação lícita ou positiva”), Gugel (2000, p. 16) define como:

Conjunto de medidas legais, modo de vida e políticas sociais que pretendem aliviar os tipos de discriminação que limitam oportunidades de determinados grupos sociais. Um esforço voluntário ou obrigatório, imposto pelo governo federal, estadual e municipal, instituições públicas ou privadas, escolas, para combater a discriminação e para promover a oportunidades na educação e acesso ao emprego.

As ações afirmativas podem ser compreendidas como "tratamento desigual imposto pela lei, para compensar a desigualdade existente na realidade", consideradas como medidas indispensáveis na busca da eliminação da desigualdade de fato com vistas a igualdade substancial, visando a redução da desigualdade (MALLET, 2010, p. 40).

Para Piovesan $(2005$, p. 49) as ações afirmativas constituem medidas especiais que objetivam acelerar o processo de alcance da igualdade substantiva pelos grupos excluídos, consistindo em medidas concretas para viabilizar o direito à igualdade, moldando-se no respeito à diversidade.

Desta forma, a interferência Estatal, por meio das chamadas ações afirmativas, tem por objetivo a busca pela igualdade de fato e na erradicação da discriminação e, conforme se pretende analisar adiante, constitui passo importante na efetivação dos direitos fundamentais, principalmente no âmbito das relações de trabalho.

\subsection{A Efetivação do Direito ao Trabalho como Direito Fundamental e a Erradicação da Discriminação no Trabalho}

A Declaração Universal dos Direitos Humanos introduziu a concepção contemporânea de direitos humanos, fundada na universalidade e indivisibilidade. Para aquela, o único requisito é a condição humana; e para a indivisibilidade os direitos humanos constituem uma unidade indivisível, interdependente e inter-relacionada (PIOVESAN, 2004, p. 21).

Ao eleger a indivisibilidade dos direitos humanos a Declaração dos Direitos Humanos (ONU, 1948) conjuga o discurso liberal e o discurso social, combinando os valores da liberdade e da igualdade. No mesmo sentido, a Declaração de Viena (ONU, 1993) traz em seu artigo $5^{\circ}$ que "todos os direitos humanos são universais, indivisíveis, interdependentes e inter-relacionados", cabendo a comunidade internacional o dever de tratar os direitos humanos globalmente de forma justa e equitativa, em pé de igualdade e com a mesma ênfase.

Verifica-se que os direitos sociais são interligados a outros direitos humanos, possuindo todos os meios e instrumentos para sua efetividade, inclusive exigibilidade judicial (MENEZES et al., 2009, p. 73), constituindo direitos fundamentais autênticos e exigíveis, que têm como objetivo a proteção aos grupos vulneráveis, demandando, além das políticas universalistas, políticas específicas a estes grupos, enquanto vítimas da exclusão (PIOVESAN, 2004, p. 26-27).

Nesse contexto, o Estado deve liderar o processo de mudanças em matéria de direitos sociais, a partir das obrigações assumidas no plano nacional e no internacional, na busca pela efetivação dos direitos humanos, dentre eles, o direito ao trabalho (PAUTASSI, 2007, p. 90). A efetivação do direito ao trabalho sem distinção e garantindo a igualdade entre os trabalhadores 
caracteriza-se, também, pela vedação de condutas que inibam o acesso ao mercado de trabalho (SOUTO MAIOR, 2002, p. 98).

Por se tratar de um direito universal (igualdade) o tema "não discriminação" no âmbito do trabalho tem destaque na Organização Internacional do Trabalho (OIT), uma vez que configura um dos seus objetivos fundamentais, conforme a Declaração de Filadélfia (OIT, [1986?], p. 20) que prescreve:

[...] todos os seres humanos de qualquer raça, crença ou sexo, têm o direito de assegurar o bem-estar material e o desenvolvimento espiritual dentro da liberdade e da dignidade, da tranquilidade econômica e com as mesmas possibilidades.

A Convenção 111 da OIT, ratificada no Brasil pelo Decreto n. 62.150/68 (BRASIL, 1968) trata, especificamente, sobre a proibição da discriminação em matéria de emprego, trazendo no artigo 1, 1.1, a definição de discriminação que compreende "toda distinção, exclusão ou preferência fundada na raça, cor, sexo, religião, opinião política, ascendência nacional ou origem social, que tenha por efeito destruir ou alterar a igualdade de oportunidade ou de tratamento em matéria de emprego ou profissão." (OIT, 1958).

Ainda, a alínea "b" do referido artigo expõe que discriminação compreende também "qualquer outra distinção, exclusão ou preferência que tenha por efeito destruir ou alterar a igualdade de oportunidades ou tratamento em matéria de emprego ou profissão" (OIT, 1958).

Segue o artigo 2 determinando que todos os Estados-membros, para os quais a Convenção esteja em vigor, devem instituir política nacional com o objetivo de erradicar toda e qualquer discriminação nesta matéria, promovendo a igualdade de oportunidades e tratamento.

A Constituição de 1988 (BRASIL, 1988), não obstante os artigos já citados anteriormente em relação à vedação da discriminação de modo geral, prevê, expressamente, a discriminação relativa ao trabalho, conforme o texto do artigo $7^{\circ}$, inciso $\mathrm{XXX}$, que proíbe a utilização de critérios como sexo, idade, cor ou estado civil para a admissão no emprego.

Ainda, na legislação brasileira, a Lei 9.029/95 (BRASIL, 1995) trata especificamente das práticas discriminatórias para efeitos de admissão e manutenção da relação de emprego, determinando no artigo $1^{\circ}$ que "fica proibida a adoção de qualquer prática discriminatória e limitativa para efeito de acesso a relação de emprego, ou sua manutenção, por motivo de sexo, origem, raça, cor, estado civil, situação familiar ou idade".

Uma vez previsto na Constituição de 1988, em tratados internacionais ratificados e nas normas infraconstitucionais, a efetivação dos direitos econômicos, sociais e culturais passa a constituir obrigação jurídica do Estado, que deverá garantir adequadamente as condições para todos os indivíduos, vinculando o particular à sua efetivação. Assim, constata-se que a não obtenção do trabalho por ato de discriminação representa lesão ao direito fundamental ao trabalho (MENEZES et al., 2009, p. 90-91).

A discriminação no trabalho, seja no processo de admissão, no decorrer da relação de emprego, bem como motivo da dispensa, não pode ser admitida, posto que o ordenamento jurídico veda a utilização de critérios discriminatórios (GOSDAL, 2003, p. 3) impondo limites constitucionais e infraconstitucionais.

A adoção destes critérios constitui-se abuso de poder do empregador e ultrapassa os limites do poder diretivo, o qual é limitado pelos dispositivos constitucionais, internacionais e infraconstitucionais, além, é claro, em afronta aos Direitos Humanos. Isso significa dizer que o empregador possui discricionariedade para contratar quem deseja dentre aqueles que se apresentam para a vaga oferecida, utilizando-se do seu poder diretivo, mas não pode deixar de contratar determinado candidato com base em critérios discriminatórios, bem como deixar de promover ou dar oportunidades na empresa ou mesmo fundar o despedimento nestes critérios, sob pena de 
afrontar os direitos humanos sociais, reconhecidamente como direito a igualdade.

\section{DISCRIMINAÇÃO NO TRABALHO EM RAZÃO DOS ANTECEDENTES CRIMINAIS}

A fim de possibilitar uma melhor discussão sobre o tema, primeiramente, entendeu-se necessário verificar qual o objetivo da manutenção de registro dos antecedentes criminais e, logo após, passa-se a analisar a existência da prática de exigência de certidão de antecedentes criminais.

Inicialmente, sobre os antecedentes criminais, esclarece-se que estes são empregados para a dosimetria da pena (art. 59, CP), decretação de prisões preventivas (art. $312 \mathrm{CPP}$ ), negação de liberdades (art. 323, III CPP) e revogação de suspensão condicional da pena (art. $709 \S 2^{\circ} \mathrm{CPP}$ ).

Verifica-se, desta forma, que o intuito da manutenção de antecedentes criminais possui interesse público, com a finalidade bem definida, uma vez que estes serão utilizados pelo juízo criminal nas hipóteses elencadas acima.

Pedrosa (2008, p. 2) afirma que:

Na era da multiplicação da população, com vinculado e inevitável agravamento dos índices de criminalidade, mormente nas chamadas "cidades grandes", é evidente que o Estado terá que contar com fórmulas de, ao menos, monitorar o passado delituoso do cidadão. Mas isso tem (ou devia ter) limites...

De fato, os referidos limites são impostos pelo Código Penal e pela Lei de Execução Penal. O artigo 64 do Código Penal determina que para efeitos de reincidência não prevalecerá condenação anterior se houver decorrido prazo de cinco anos entre a data do cumprimento ou extinção da pena e a infração posterior, computado o período de prova da suspensão ou do livramento condicional, se não ocorrer revogação. Assim, transcorrido o referido prazo, as condenações anteriores não poderão ser levadas em consideração em novo processo.

A Lei de Execução Penal (BRASIL, 1984, grifo nosso), por sua vez, determina no artigo 202 que

[...] cumprida ou extinta a pena, não constarão da folha corrida, atestados ou certidões fornecidas por autoridade policial ou por auxiliares da Justiça, qualquer notícia ou referência à condenação, salvo para instruir processo pela prática de nova infração penal ou outros casos expressos em lei [...].

É possível inferir que o ordenamento jurídico brasileiro é contrário à manutenção eterna de antecedentes criminais, principalmente se considerar que a Constituição de 1988 (BRASIL, 1988) prevê, no artigo $5^{\circ}$, inciso XLVII, a vedação de penas de caráter perpétuo. Sendo assim, é razoável que tenha sido estabelecido o prazo (da reincidência) para manutenção dos referidos antecedentes, sob pena de se institucionalizar a eternização da condenação do réu.

No que se refere à existência de prática de exigência de certidão de antecedentes criminais, foi realizada uma pesquisa quantitativa, no âmbito do Patronato Municipal de Apucarana, durante os meses de junho e agosto de 2014, com 20 (vinte) assistidos. Para melhor contextualização da escolha do público-alvo da pesquisa e local, inicialmente, traça-se um breve histórico do Patronato de Apucarana. Após, esclarecer-se-á a metodologia e os resultados alcançados.

\subsection{O Patronato de Apucarana - Estado do Paraná}

O Patronato é órgão de execução penal que se destina ao acompanhamento de egressos 
e beneficiários de medidas e penas alternativas, denominados assistidos, promovendo ações afirmativas de inclusão social.

Em 2013 foi criado o Programa de Municipalização das Penas e Medidas em Meio Aberto, cuja estrutura era baseada na parceria entre a Secretaria de Estado da Justiça, Cidadania e Direitos Humanos (SEJU), a Secretaria de Estado da Ciência, Tecnologia e Ensino Superior (SETI) e Prefeituras Municipais e Conselhos da Comunidade, do qual resultou os Patronatos Municipais (PARANÁ, 2014).

Da parceria entre SEJU e SETI originou-se o projeto de extensão universitária, sob a supervisão do Patronato Central do Estado do Paraná, por meio do qual são compostas as equipes multidisciplinares que atuam nos Patronatos Municipais, constituídas por profissionais recémformados e estagiários das áreas de Direito, Serviço Social, Psicologia e Pedagogia, bem como estagiários da área de Administração de Empresas. Atualmente, a estrutura é composta pela Secretaria de Estado de Segurança Pública e Administração Penitenciária (SESP), uma vez que o Departamento de Execução Penal - DEPEN -, órgão ao qual os Patronatos Municipais estão vinculados, foi transferido para esta secretaria no ano de 2014 (PARANÁ, 2014).

O Patronato Municipal de Apucarana foi criado pela Lei Municipal 66/2013. Ao Patronato Municipal de Apucarana incumbe o acompanhamento e fiscalização do cumprimento das penas e medidas alternativas, bem como do regime aberto e semiaberto em prisão domiciliar.

Em Apucarana as alternativas penais consistem, em sua maioria, na prestação de serviços à comunidade, mas também são aplicadas através de inserção em grupos socioeducativos, em ensino regular, em cursos profissionalizantes, bem como participação em palestras informativas.

Em relação à educação há no Poder Judiciário a preferência pelo encaminhamento à educação formal - EJA e CEEBJA - e cursos profissionalizantes. Aos assistidos que possuem ensino médio completo as opções são de cursos superiores e financiamento estudantil.

Nos grupos socioeducativos foram executados vários projetos de destaque, dentre os quais, o "Projeto Saiba", destinado a usuários de drogas; o "Projeto Plural", voltado a assistidos que cometeram delitos diversos e apresentam em comum a necessidade de reflexão; o "Projeto Novos Horizontes" voltado a homens autores de violência doméstica, aos quais foram aplicadas medidas protetivas da Lei Maria da Penha; e o "Projeto PensAção", desenvolvido com os apenados em regime semiaberto, na modalidade de prisão domiciliar.

\subsection{Prática discriminatória: a pesquisa com os assistidos do Patronato de Apucarana}

Consoante exposto, entre os meses de junho e agosto de 2014 foi realizada uma pesquisa com os assistidos, sendo estes condenados em cumprimento de pena em regime aberto, pelo Patronato Municipal de Apucarana, em relação ao acesso ao mercado de trabalho, cuja metodologia foi a quantitativa, através da aplicação de um questionário, com o objetivo de identificar se há exigência ou mesmo indagações sobre a existência de antecedentes criminais na fase pré-contratual do contrato de trabalho e se este motivo, caso positivo, foi importante, na visão dos assistidos, para a sua não contratação.

No referido questionário foi, inicialmente, questionado qual a situação de trabalho em que se encontra e qual sua função. A partir da situação que se encontra, foram postas as seguintes questões: se desempregado ou se em situação informal de trabalho, a que motivo ele(a) atribui a referida situação? Ainda, foi questionado se, em processo de admissão, já houve resposta negativa expressa da empresa com base na certidão de antecedentes criminais e se ele(a) entende que, não havendo resposta explícita, o motivo da não contratação seria este.

O questionário permite a resposta de mais de um motivo apresentado pela empresa, assim como os motivos que ele atribui à negativa da empresa, caso esta não tenha sido clara.

Desta forma, foram aplicados questionários a 20 (vinte) assistidos pelo Patronato Municipal 
de Apucarana, sendo que destes 18 (dezoito) são do gênero masculino e 2 (dois) do gênero feminino.

Analisando as respostas, constatou-se, incialmente, que 2 (dois) assistidos estavam desempregados, 4 (quatro) estavam empregados informalmente (sem registro em CTPS), 8 (oito) estavam empregados com registro em CTPS e 6 (seis) eram trabalhadores autônomos.

Aos desempregados foi questionado o motivo do desemprego, sendo obtidas as seguintes respostas: "falta de oportunidade, pois acabei de sair do mini-presídio"; "não parei nos últimos empregos, mas não sei o porquê".

Os autônomos e empregados informais sem registro em CTPS, que totalizam 10 (dez) assistidos, foram indagados sobre o motivo de não serem empregados registrados, as respostas foram: "autônomo por opção", "prefiro não ter registro", "por causa da condenação"; "por falta de oportunidade"; "por opção do empregador"; "onde trabalho não registram"; "porque estou recebendo seguro-desemprego"; "por causa dos descontos que são feitos quando registram"; e 2 (dois) não souberam responder.

Sobre as funções exercidas, entre autônomos e empregados, com ou sem registro em CTPS, estes declararam ser: 6 (seis) serventes de pedreiro, 1 vidraceiro, 1 repositor, 1 auxiliar de serviços gerais, 1 gesseiro, 1 trabalhava com ferragens, 1 auxiliar de acabamento, 1 trabalhava num lavajato, 1 costureira, 1 armador, 1 motorista, 1 bordador e 1 mecânico de manutenção industrial.

Entre os 20 (vinte) assistidos entrevistados, 12 (doze) já receberam resposta negativa em processo de admissão. Dentre estas, foram elencadas as seguintes: não informou o motivo (4); possuir antecedentes Criminais (2); vaga foi preenchida (3); empregador sabia da condenação judicial (1); falta de experiência profissional (1); não havia vagas (1).

Ainda, em relação a estas respostas negativas, quando questionados sobre os motivos que acreditam ter levado a esta resposta negativa (e não o motivo informado pelo contratante), os assistidos, dentre os motivos apresentados no questionário, elencaram os seguintes: possuir antecedentes criminais (7); falta de experiência profissional (3); ausência de formação acadêmica (2); teste psicotécnico (1); discriminação em razão do empregador saber da condenação (1); estar em situação de rua, morando em abrigo (1).

Não obstante a limitação da pesquisa em relação à quantidade de assistidos, a intenção, primordial, desta foi constatar a existência da prática de exigência da certidão de antecedentes criminais em processo seletivo de admissão, constituindo obstáculo, ou não, para a referida contratação.

Pois bem: uma vez compreendido o objetivo do registro de antecedentes criminais e analisando os dados obtidos por amostragem, bem como a bibliografia, acima descritos, retoma-se a questão anterior: constitui conduta discriminatória a sua exigência em processo seletivo, prática constatada na pesquisa com os assistidos do Patronato de Apucarana?

Sobre a situação identificada, esclarece Pedrosa $(2008$, p. 6) é notório que os egressos do sistema penitenciário possuem dificuldade ou até impossibilidade de conseguirem empregos formais em razão da não obtenção da "folha corrida" ou "Declaração de Bons Antecedentes".

Especificamente, em relação à constituição de prática discriminatória, deve-se recordar que os critérios definidos pela Constituição de 1988 em relação à discriminação no trabalho, elencados pelo art. $7^{\circ}, \mathrm{XXX}$, bem como os critérios elencados pela Lei 9.029/95, são meramente exemplificativos, uma vez que, realizada a interpretação conjugada com outros dispositivos constitucionais, conclui-se, desde já, que são vedadas quaisquer formas de discriminação.

$\mathrm{Na}$ visão de Gosdal (2003, p. 6) na conduta praticada não há proporção entre o valor objetivado e o valor sacrificado, pois não é possível compreender que a tutela da iniciativa privada, no que se refere ao poder diretivo do empregador, esteja acima ao princípio da igualdade e da não discriminação, os quais são matéria de ordem pública.

Não poderíamos dizer que há correlação lógica entre a conduta e as normas e 
valores legais e constitucionais vigentes, [...] a finalidade da folha de antecedentes criminais é resguardar o interesse público e instrumentalizar a persecução criminal, havendo vedação expressa de qualquer forma de discriminação e interesse na eliminação da exclusão social (GOSDAL, 2003, p. 4).

Pereira (2016, p. 9) acrescenta que "a liberdade contratual não pode obstar de modo ilícito a liberdade de trabalhar de cada indivíduo". Este "direito ao esquecimento", afastando a perpetuação da pena, é imprescindível para que determinadas pessoas não sejam estigmatizadas ou discriminadas, uma vez que, se fosse possível a eternização da pena, a marginalização de um grupo de pessoas seria um risco grande, fato que não é desejável à sociedade (MALLET, 2010, p. $33)$.

O processo de admissão deve guardar conformidade com a Constituição de 1988, com os tratados internacionais ratificados pelo Brasil, com a legislação infraconstitucional e, principalmente, com os Direitos Humanos, dentre os quais a igualdade e da dignidade da pessoa humana, buscando não excluir um determinado grupo de pessoas do mercado de trabalho formal, possibilitando, desta forma, a valorização social do trabalho e, por conseguinte, a justiça social.

Não foi o que se verificou na pesquisa realizada, pois, frente aos dados retro expostos, verificou-se que há 1 (um) desempregado por causa da condenação, 2 (dois) assistidos tiveram negativas sem qualquer justificativa, 2 (dois) assistidos tiveram negativas expressas em razão dos antecedentes criminais, 1 (um) assistido teve uma negativa pelo seu empregador saber da condenação. A situação muda quando estes são questionados sobre a possível motivação das negativas, pois 7 (sete) assistidos atribuem à apresentação de antecedentes criminais, reiterando que a certidão foi exigida nos referidos processos seletivos.

O princípio da não-discriminação deve nortear todo o processo seletivo, constituindo limite à invasão da intimidade do empregado (GOSDAL, 2003, p. 8). Como ressalta Gosdal (2003, p. 4) a identidade do cidadão está associada ao trabalho, sendo que a reinserção no mercado de trabalho constitui o caminho de retorno à sua dignidade e efetiva recuperação.

Pereira (2016, p. 12), em análise da jurisprudência dos tribunais do trabalho brasileiros, leciona que há divergência na jurisprudência, mas que, em geral, ao decidir sobre a contraposição destes dois princípios constitucionais, a jurisprudência tem conferido efetividade ao princípio do amplo acesso a informações públicas oficiais nos casos que as informações sejam essenciais para o exercício da atividade profissional, como, por exemplo, nas funções de vigilantes armados.

Em razão da divergência jurisprudencial, em 28 de junho de 2016 o Tribunal Superior do Trabalho realizou audiência pública sobre o tema, buscando subsídios para a decisão de dois Recursos de Revista1, submetidos à Subseção 1 Especializada de Dissídios Individuais, com tramitação sob o rito dos recursos repetitivos, ou seja, firmando precedente judicial e tornando-os paradigmas para a solução de lides que versarem sobre esta questão.

No julgamento dos incidentes de recurso de revista repetitivos (tema $n^{\circ} 01$ ), acima indicados, foi decidido que a exigência de certidão negativa de antecedentes criminais caracteriza dano moral passível de indenização em situações excepcionais, de exigência de certidões de antecedentes criminais para casos previstos em lei (vigilantes) ou quando o cargo exige especial fidúcia (confiança) (AGUIAR, 2016)².

1 RRs 243000-58.2013.5.13.0023 e 184400-89.2013.5.13.0008, ambos de relatoria do Ministro Márcio Eurico Vitral Amaro.

2 Nos julgamentos foram fixadas as teses seguintes: 1. Não é legítima, e caracteriza lesão moral, a exigência de certidão de antecedentes criminais de candidato a emprego quando traduzir tratamento discriminatório ou não se justificar em razão de previsão em lei, da natureza do ofício ou do grau especial de fidúcia exigido; 2 . A exigência de certidão de candidatos a emprego é legítima e não caracteriza lesão moral quando amparada em expressa previsão legal ou justificar-se em razão da natureza do ofício ou do grau especial de fidúcia exigido, a exemplo de empregados domésticos, cuidadores de menores, idosos e pessoas com deficiência, em creches, asilos ou instituições afins, motoristas rodoviários de carga, empregados que laboram no setor da agroindústria no manejo de ferramentas de 
Não obstante o entendimento do Tribunal Superior do Trabalho, em casos específicos, a partir das considerações realizadas sobre o tema, conclui-se que tal exigência constitui prática discriminatória, configurando abuso de poder do empregador. O processo seletivo para admissão de empregado deve ter como base o princípio constitucional da igualdade, devendo, ainda, esta situação ser objeto de ações afirmativas. Ademais, a referida exigência encontra-se em sentido contrário ao que prevê a política criminal brasileira, tema objeto de análise do tópico seguinte.

\subsection{Ressocialização e política criminal brasileira}

A política criminal brasileira está centrada na ressocialização do egresso do sistema penitenciário, na possibilidade de modificar e não voltar a delinquir. Consoante o Plano Nacional de Política Criminal e Penitenciária (BRASIL, 2011), aprovado na $372^{\mathrm{a}}$ reunião ordinária do Conselho Nacional de Política Criminal e Penitenciária (CNPCP) em 26/04/2011, o caminho adotado é de cidadania e responsabilização social, buscando a redução das taxas de encarceramento, da justiça social e priorizando as penas alternativas à prisão.

A criação e implantação de uma política de integração social dos egressos do sistema prisional constitui uma das prioridades do referido plano, posto que a inexistência de ações afirmativas de ressocialização do egresso do sistema penitenciário na sociedade, particularmente no mercado de trabalho, é considerado, pelo Ministério da Justiça, como um dos principais fatores da reincidência recorrente e do aumento da população encarcerada (BRASIL, 2011).

Para aplicação desta medida, o plano apresentado pelo Ministério da Justiça (BRASIL, 2011) requer: a) Elaboração e implantação de programa integrado com outros Ministérios e Poderes, que envolva ações sociais, familiares, educacionais e laborais; b) Incentivo fiscal concedido às empresas que contratam egressos; c) Efetivação da assistência à educação, a capacitação profissional e laboral nas unidades prisionais, vinculando-as com ações para os egressos.

Assim, constata-se que a política penitenciária brasileira se pauta na ressocialização do egresso, tendo no trabalho o principal fator de integração social, com o objetivo da redução da reincidência, da violência e da criminalidade, bem como do poder de persuasão e de agenciamento de pessoas pelos grupos organizados do crime.

Em 2014 foi lançado o Levantamento Nacional de Informações Penitenciárias - InfoPen (BRASIL, 2016a) - que consiste em um relatório descritivo e analítico com informações detalhadas sobre a atual situação do sistema penitenciário brasileiro.

$\mathrm{Na}$ apresentação do levantamento, constata-se que o Brasil possui uma taxa de 300 presos para cada 100 mil habitantes, superando a taxa mundial de 144 presos e, em relação ao número absoluto, tem-se mais de 622 mil pessoas presas, saltando de noventa mil presos no início da década de noventa para mais de seiscentos mil em menos de 25 anos (BRASIL, 2016a).

No que se refere ao perfil do preso, no referido Levantamento (BRASIL, 2016a) verificouse que: a) a maioria é constituída de jovens $(55,07 \%$ da população privada de liberdade tem até 29 anos); b) há uma sobrerrepresentação de negros (61,67\% da população presa); c) há uma população com precário acesso à educação (apenas 9,5\% concluíram o ensino médio, enquanto a média nacional gira em torno de $32 \%$ ); d) pessoas analfabetas, alfabetizadas informalmente mais aquelas que têm até o ensino fundamental completo representam $75,08 \%$ da população prisional.

Com base no relatório (BRASIL, 2016a), o enfrentamento mais adequado aos problemas penitenciários pode ser dividido em quatro eixos: redução do déficit de vagas; redução do déficit de gestão; potencialização das políticas de reintegração e modernização.

A política criminal brasileira, pautada na ressocialização, vai, portanto, em sentido contrário

trabalho perfurocortantes, bancários e afins, trabalhadores que atuam com substâncias tóxicas e entorpecentes e armas, trabalhadores que atuam com informações sigilosas; 3. A exigência da certidão de antecedentes criminais, quando ausentes alguma das justificativas de que trata o item 2, caracteriza dano moral in re ipsa [presumido], passível de indenização, independentemente de o candidato ao emprego ter ou não sido admitido. 
a se inserir-se como requisito a apresentação de registro de antecedentes criminais em processo seletivo de admissão. Todavia, não para por aí e, conforme abordado em tópico anterior, trata da discriminação positiva ou ação afirmativa, ao dispor que deve haver a potencialização das políticas de reintegração.

Conforme explanado anteriormente, considerada prática discriminatória e, prevista a ressocialização do egresso na política criminal brasileira, ressalta-se que é necessário também o desenvolvimento de ações afirmativas de reintegração (ou mesmo integração) no mercado de trabalho.

\subsection{Ações afirmativas: Projeto de Lei do Senado 70/10 e Programa Começar de Novo}

As ações afirmativas ocupam um papel de suma importância dentre de uma sociedade que privilegia, dentre os seus principais princípios, o Estado Democrático e Social de Direito, posto que objetivam a inclusão social, inclusive em relação ao acesso ao trabalho, enquanto direito fundamental social.

Para que a lei faça a distinção de situações sem ofensa à isonomia, Bandeira de Mello (2004, p. 43) assevera que é necessário que os fundamentos (fáticos e lógicos) se orientem na linha de interesses prestigiados pela Constituição na ordenação jurídica máxima. No presente caso, a Constituição insere o valor do trabalho como fundamento da república no artigo $1^{\circ}$, IV e como fundamento da ordem econômica, artigo 170, caput.

Se a Constituição privilegia o valor social do trabalho, constituindo fator de integração do cidadão como sujeito ativo na sociedade, é indiscutível que a exigência de antecedentes criminais no processo de admissão, conforme foi possível constatar na pesquisa, deve ser considerada como prática discriminatória, e, com vistas a garantir a isonomia de tratamento, se faz necessária a fomento de ações afirmativas com o objetivo de garantir a isonomia de tratamento.

Assim, frente à situação deste grupo específico e a necessidade de garantia do direito ao trabalho, discorre-se, brevemente, que são poucas as iniciativas para inserção de egressos do sistema penitenciário no mercado de trabalho.

Destaca-se, como exemplo, o Projeto de Lei do Senado 70/2010 (BRASIL, 2010) que dispõe sobre a dedução dos encargos sociais devidos pelas pessoas jurídicas tributadas com base no lucro real, em caso de contratação de egressos do sistema prisional, proposto pela Senadora Marisa Serrano, aprovado na Comissão de Assuntos Sociais e que obteve parecer favorável do Senador José Agripino na Comissão de Assuntos Econômicos. Todavia, o projeto foi arquivado, em razão do final da 54ª legislatura (2011-2015), nos termos do artigo 332 do Regimento Interno do Senado Federal ${ }^{3}$.

Em sua justificativa, o projeto abordava como ponto principal a dificuldade de inserir os egressos no sistema carcerário no mercado de trabalho, ocasionando a falta do exercício à cidadania plena, configurando grave problema social.

Outro projeto de destaque, foi o elaborado pelo Conselho Nacional de Justiça em 2009 Programa Começar de Novo -, o qual tinha por objetivo a promoção da cidadania e diminuição da reincidência criminal, por meio da sensibilização de órgãos públicos e da sociedade civil através do incentivo à disponibilização de vagas de trabalho e cursos de capacitação profissional aos presos e egressos do sistema carcerário.

Consoante a Cartilha do Empregador (CNJ, 2011, p. 13) elaborada pelo Programa

Muitas vezes a sociedade não quer lidar com a situação dessas pessoas e adotam uma postura de isolamento. No entanto, essa imensa população carcerária voltará

$3 \mathrm{O}$ artigo 332 do Regimento Interno do Senado Federal estabelece que os projetos de lei em tramitação no Senado serão arquivados ao final da legislatura, com algumas exceções previstas nos incisos do referido artigo. 
às ruas e ao convívio em sociedade. É preciso agir de forma a possibilitar que o retorno seja positivo para todos e eles possam ser somados à sociedade, reduzindo os índices de violência.

Desta forma, o Conselho Nacional de Justiça criou o Portal de Oportunidades, site que disponibiliza os postos de trabalho e cursos de capacitação oferecidos para presos e egressos do sistema penitenciário. Neste caso sempre haverá um intermediador entre candidato e empresa.

Retomando-se a atuação do Patronato de Apucarana, no Estado do Paraná, os responsáveis pela intermediação e aplicação do Programa Começar de Novo são os Patronatos (Patronato Central do Estado e os Patronatos Municipais, como por exemplo, o de Apucarana), devendo estes estabelecer parcerias com empresas e consequente cadastro no Portal de Oportunidades, realizar capacitações para o mercado de trabalho por meio de palestras informativas e efetuar encaminhamentos para cursos de capacitação.

Ainda, no ano de 2016, o Tribunal Superior Eleitoral lançou o Projeto Começar de Novo no âmbito da Justiça Eleitoral, fornecendo postos de trabalho aos presos e egressos do sistema penitenciário. De acordo com o TSE, a ideia é que os Tribunais Regionais Eleitorais recrutem esses profissionais para trabalhar nos órgãos da Justiça Eleitoral (BRASIL, 2016b).

Indiscutivelmente, não obstante esteja clara a existência da prática discriminatória, são poucas as iniciativas de políticas públicas com o objetivo da ressocialização através do incentivo à inserção deste grupo específico no mercado de trabalho.

\section{CONCLUSÃO}

Em épocas de crise social e, por conseguinte, do Estado Democrático de Direito, os valores são, cada vez mais, colocados em conflitos. Mas, indiscutivelmente, os valores individuais (principalmente da dignidade da pessoa humana) e os sociais (igualdade, dentre outros) estabelecidos na Constituição de 1988 e os reconhecidos pelos Direitos Humanos não podem ser objetos de desapropriação do ser humano, sob pena de inversão completa dos princípios e dos valores fundamentais de um Estado Democrático e Social de Direito.

Foi possível constatar, seja pela pesquisa realizada in loco no Patronato de Apucarana, pelas discussões através de audiências públicas ou de decisões no TST, que a exigência de certidão de antecedentes criminais ou mesmo de pergunta sobre a existência de antecedentes criminais é uma realidade que ocorre quando da contratação.

Nesse contexto, não se pode admitir a possibilidade qualquer ou quaisquer instrumentos ou obstáculos de acesso aos cidadãos, principalmente os mais desfavorecidos e desprotegidos, ao mercado de trabalho e, nesse sentido, a exigência de certidão de antecedentes criminais ou mesmo a não contratação dos trabalhadores por estarem em cumprimento de pena (regime aberto ou semiaberto) constituiu afronta ao princípio da igualdade, bem como da dignidade da pessoa humana.

Não obstante, não basta apenas reconhecer que a respectiva conduta (exigir a certidão de antecedentes criminais) é uma prática discriminatória, motivo pelo qual se verifica a necessidade de implantação de ações afirmativas, buscando a garantia de igualdade de oportunidades ao egresso do sistema carcerário no que se refere ao acesso ao trabalho, oportunizando, de fato, a realização do princípio da igualdade material.

Por fim, resta claro que o objetivo do presente artigo não foi o de traçar conclusões definitivas a respeito da marginalização deste grupo específico, mas de concluir sobre a natureza de discriminação (ou não) da uma determinada prática, incentivando, sobretudo, a comunidade jurídica e a sociedade a uma discussão mais ampla a respeito do tema proposto, buscando, através do debate e do exercício da Democracia, a dignidade da pessoa humana. 


\section{REFERÊNCIAS}

AGUIAR, Adriana. TST define que empresa não pode exigir antecedentes criminais. Valor Econômico, São Paulo, 2016. Disponível em: www.valor.com.br/legislação/4946102/tst-defineque-empresa-nao-pode-exigir-antecedentes-criminais. Acesso em: 23 abr. 2017.

BRASIL. [Constituição (1988)]. Constituição da República Federativa do Brasil de 1988. Brasília: Presidência da República, 1988. Disponível em: http://www.planalto.gov.br/ccivil_03/ constituicao/constituicao.htm. Acesso em: 11 maio 2015.

BRASIL. Decreto $\mathbf{n}^{\circ}$ 62.150, de 19 de janeiro de 1968. Promulga a Convenção ${ }^{\circ} 111$ da OIT sôbre discriminação em matéria de emprêgo e profissão. Brasília: Presidência da República, 1968. Disponível em: http://www.planalto.gov.br/ccivil_03/decreto/1950-1969/D62150.htm. Acesso em: 12 maio 2015.

BRASIL. Lei n 7.210, de 11 de julho de 1984. Institui a Lei de Execução Penal. Disponível em: http://www.planalto.gov.br/ccivil_03/leis/17210.htm. Acesso em: 11 maio 2015.

BRASIL. Lei n 9.029, de 13 de abril de 1995. Pró́be a exigência de atestados de gravidez e esterilização, e outras práticas discriminatórias, para efeitos admissionais ou de permanência da relação jurídica de trabalho, e dá outras providências. Brasília: Presidência da República, 1995. Disponível em: http://www.planalto.gov.br/ccivil_03/leis/19029.htm. Acesso em: 12 maio 2015.

BRASIL. Ministério da Justiça. Conselho Nacional de Política Criminal e Penitenciária. Plano nacional de política criminal e penitenciária. Brasília: CNPCP, 2011. Disponível em: http:// www.tjrj.jus.br/documents/10136/3231852/plano-politica-criminal-penitenciaria-2011.pdf. Acesso em: 18 jun. 2015.

BRASIL. Ministério da Justiça. Departamento Penitenciário Nacional. Levantamento nacional de informações penitenciárias INFOPEN: dezembro 2014. Brasília: DEPEN, 2016a. Disponível em: https://www.conjur.com.br/dl/infopen-dez14.pdf. Acesso em: 27 maio 2016.

BRASIL. Projeto de Lei do Senado $\mathbf{n}^{\circ}$ 70, de 2010. Dispõe sobre a dedução dos encargos sociais devidos pelas pessoas jurídicas tributadas com base no lucro real, em caso de contratação de egressos do sistema prisional, e dá outras providências. Brasília: Senado Federal, 2010. Disponível em: http://www.senado.gov.br/atividade/materia/detalhes.asp?p_cod_mate $=96017$. Acesso em: 27 maio 2016.

BRASIL. Tribunal Superior Eleitoral. Projeto Começar de Novo será lançado nesta terçafeira (24) na Justiça Eleitoral. Brasília: TSE, 2016b. Disponível em: http://www.tse.jus.br/imprensa/ noticias-tse/2016/Maio/programa-comecar-de-novo-na-justica-eleitoral-sera-lancado-nesta-terca-feira-24. Acesso em: 27 maio 2016.

CNJ - CONSELHO NACIONAL DE JUSTIÇA. Cartilha do empregador. Brasília: CNJ, 2011. Disponível em: https://www.cnj.jus.br/wp-content/uploads/2011/10/cartilha_do_empregador_1. pdf. Acesso em: 3 jul. 2015.

GOSDAL, Thereza Cristina. Antecedentes criminais e a discriminação no trabalho. Revista do Tribunal Regional do Trabalho da 9a Região, Curitiba, v. 28, n. 49, p. 227-258, jan./jun. 2003. 
GUGEL, Maria Aparecida. Discriminação positiva. Revista do Ministério Público do

Trabalho, Brasília, v. 10, n. 19, p. 15-24, mar. 2000.

MALLET, Estêvão. Igualdade e discriminação em Direito do Trabalho. São Paulo: LTr, 2013.

MALLET, Estêvão. Igualdade, discriminação e Direito do Trabalho. Revista do Tribunal Superior do Trabalho, Brasília, v. 76, n. 3, p. 17-51, jul./set. 2010.

MELLO, Celso Antônio Bandeira de. Conteúdo jurídico do princípio da igualdade. 3. ed. São Paulo: Malheiros, 2004.

MENEZES, Cláudio Armando Couce de et al. As garantias dos direitos sociais e laborais e as dimensões de sua efetividade: direito ao trabalho e a não discriminação: medidas judiciais e pretensões cabíveis. Revista do Tribunal Regional do Trabalho da $3^{\text {a }}$ Região, Belo Horizonte, v. 50, n. 80, p. 73-94, jul./dez. 2009.

OIT - ORGANIZAÇÃO INTERNACIONAL DO TRABALHO. C111: discriminação em matéria de emprego e ocupação. Brasília: OIT, 1958. Disponível em: https://www.ilo.org/brasilia/ convencoes/WCMS_235325/lang--pt/index.htm. Acesso em: 12 maio 2015.

OIT - ORGANIZAÇÃO INTERNACIONAL DO TRABALHO. Constituição da Organização Internacional do Trabalho (OIT) e seu anexo (declaração de Filadélfia). Brasília: OIT, [1986?]. Disponível em: https://www.ilo.org/wcmsp5/groups/public/---americas/---ro-lima/---ilo-brasilia/ documents/genericdocument/wcms_336957.pdf. Acesso em: 12 maio 2015.

ONU - ORGANIZAÇÃO DAS NAÇÕES UNIDAS. Declaração e programa de ação de Viena (1993). Viena: ONU, 1993. Disponível em: http://www.pge.sp.gov.br/centrodeestudos/ bibliotecavirtual/instrumentos/viena.htm. Acesso em: 13 maio 2015.

ONU - ORGANIZAÇÃO DAS NAÇÕES UNIDAS. Declaração Universal dos Direitos Humanos. Paris: Assembleia Geral das Nações Unidas, 1948. Disponível em: https://www. ohchr.org/EN/UDHR/Documents/UDHR_Translations/por.pdf. Acesso em: 13 maio 2015.

PARANÁ. Secretaria da Segurança Pública e Administração Penitenciária. Departamento Penitenciário. Patronato Central do Estado. Programa Patronato: programa de municipalização do acompanhamento das penas e medidas alternativas em meio aberto. Curitiba: DEPEN, 2014. Disponível em: http://www.depen.pr.gov.br/modules/conteudo/conteudo.php?conteudo=217. Acesso em: 2 maio 2015.

PAUTASSI, Laura Cecilia. Há igualdade na desigualdade? Abrangência e limites das ações afirmativas. Sur: Revista Internacional de Direitos Humanos, São Paulo, v. 4, n. 6, p. 70-93, 2007.

PEDROSA, Ronaldo Leite. Folha penal perpétua. [S. l.], 2008. Disponível em: http://www.tjrj.jus.br/c/document_library/get_file?uuid=66c257b7-bd44-4564-a3bc6ddefcff61 2 \& groupId=10136. Acesso em: 2 jun. 2015.

PEREIRA, Flávia Alejandra Fernández. Exigência de certidão de antecedentes criminais na contratação de empregado: violação de direitos fundamentais do trabalhador ou exercício do poder diretivo do empregador. In: SEMINÁRIO NACIONAL DEMANDAS SOCIAIS E POLÍTICAS PÚBLICAS NA SOCIEDADE CONTEMPORÂNEA, 12., 2016, Santa Cruz do 
Sul. Anais [...]. Santa Cruz do Sul: UNISC, 2016. Disponível em: https://online.unisc.br/acadnet/ anais/index.php/snpp/article/view/14733/3561. Acesso em: 15 fev. 2018.

PIOVESAN, Flavia. Ações afirmativas da perspectiva dos direitos humanos. Cadernos de Pesquisa, São Paulo, v. 35, n. 124, p. 43-55, jan./abr. 2005.

PIOVESAN, Flavia. Direitos sociais, econômicos e culturais e direitos civis e políticos. Sur: Revista Internacional de Direitos Humanos, São Paulo, v. 1, n. 1, p. 20-47, 2004.

ROTHENBURG, Walter Claudius. Igualdade material e discriminação positiva: o princípio da isonomia. Novos Estudos Jurídicos, Itajaí, v. 13, n. 2, p. 77-92, jul./dez. 2008.

SOUTO MAIOR, Jorge Luiz. O direito do trabalho e as diversas formas de discriminação, Revista do Tribunal Superior do Trabalho, Brasília, v. 68, n. 2, p. 97-102, abr./jun. 2002.

Como citar: PAULA, Bruna Balthazar de; RIBEIRO, Luiz Alberto Pereira. Discriminação no trabalho e antecedentes criminais: ações afirmativas e estudo de caso no patronato municipal de Apucarana - Paraná. Revista do Direito Público, Londrina, v. 15, n. 1, p. 10-25, abr. 2020. DOI: 10.5433/24157-108104-1.2020v15n1p. 10. ISSN: 1980-511X

Recebido em: 27/07/2016

Aprovado em: 14/02/2020 